\title{
Maternal investment, sibling competition, and offspring survival with increasing litter size and parity in pigs (Sus scrofa)
}

\author{
Inger Lise Andersen • Eric Nævdal • Knut Egil Bøe
}

Received: 29 October 2010 /Revised: 17 November 2010 /Accepted: 24 November 2010 /Published online: 12 January 2011

(C) The Author(s) 2011. This article is published with open access at Springerlink.com

\begin{abstract}
The aim of this study was to examine the effects of litter size and parity on sibling competition, piglet survival, and weight gain. It was predicted that competition for teats would increase with increasing litter size, resulting in a higher mortality due to maternal infanticide (i.e., crushing) and starvation, thus keeping the number of surviving piglets constant. We predicted negative effects on weight gain with increasing litter size. Based on maternal investment theory, we also predicted that piglet mortality would be higher for litters born late in a sow's life and thus that the number of surviving piglets would be higher in early litters. As predicted, piglet mortality increased with increasing litter size both due to an increased proportion of crushed piglets, where most of them failed in the teat competition, and due to starvation caused by increased sibling competition, resulting in a constant number of survivors. Piglet weight at day 1 and growth until weaning also declined with increasing litter size. Sows in parity four had higher piglet mortality due to starvation, but the number of surviving piglets was not affected by parity. In conclusion, piglet mortality caused by maternal crushing of piglets, many of which had no teat success, and starvation caused by sibling competition, increased with increasing litter size for most sow parities. The constant
\end{abstract}

Communicated by F. Trillmich

I. L. Andersen $(\square) \cdot$ K. E. Bøe

Department of Animal and Aquacultural Sciences,

Norwegian University of Life Sciences,

P.O. Box 5003, 1432 Ås, Norway

e-mail: inger-lise.andersen@mb.no

E. Nævdal

Frisch Centre,

Gaustadalléen 21,

0349 Oslo, Norway number of surviving piglets at the time of weaning suggests that 10 to 11 piglets could be close to the upper limit that the domestic sow is capable of taking care of.

Keywords Sows · Piglet survival · Maternal behaviour . Litter size

\section{Introduction}

Most evolutionary models assume that there is a trade-off between the number of offspring and the fitness of each of them (e.g., Lack 1947; Smith and Fretwell 1974; Lessells 1991). This fitness reduction may be a consequence of reduced maternal care, of an increased level of sibling competition, or both mechanisms may be acting at the same time. The level of this trade-off will be determined by the resources available.

Throughout the animal kingdom, parents commonly produce more zygotes than they can afford to raise (Kozlowski and Stearns 1989). Overproduction of young may increase parental fitness, either by allowing the mother to take advantage of a sudden increase in resource availability (when raising extra young is suddenly affordable), by means of sibling facilitation, or by the availability of "extras" to replace offspring that die or develop poorly (Mock and Forbes 1995; Mock and Parker 1997, 1998; Forbes and Mock 1998). Moreover, parents capable of raising their entire brood may still choose not to if this would increase their residual reproductive value for investing in future offspring (e.g., Williams 1966; Smith and Fretwell 1974).

Lack (e.g., 1947) was the first to develop a hypothesis concerning the evolution of clutch size in birds. He suggested that as brood size increased, each of the offspring 
would receive less food and become less likely to survive. As a result of this, an intermediate clutch size may produce the greatest number of survivors. Some later studies in birds confirmed that clutch size was negatively correlated with birth weight and weight gain in fledglings (e.g., Nur 1984). Subsequent authors have also shown that, in both avian and mammalian species, offspring in large broods often have lower weight, reduced growth rate, and a slower physical development than in small broods (e.g., Mendl 1988; Nilsson and Gårdmark 2001). Some studies have reported that brood size is not consistently related to offspring survival (e.g., Nur 1984). However, several others have found clear, negative effects of brood size on survival (e.g., Gustafsson and Sutherland 1988; Smith et al. 1989). If survival probabilities are unpredictable from 1 year to another, restrained reproductive effort may be favored, disturbing the expected relationship between brood size and survival. In domesticated species, environmental conditions are likely to be more predictable. For instance, in domestic poultry (Gallus gallus) and pigs (Sus scrofa) that have a history of artificial selection for increased brood size, genetic correlations between brood size, and survival are generally negative (e.g., Hogsett and Nordskog 1958; Emsley et al. 1977; Lund et al. 2002).

As discussed by Drake et al. (2008), a strategy of producing large broods and smaller young, resulting in a higher mortality rate, fits the picture of domestic pigs remarkably well. Pigs give birth to large litters. The average litter size in domestic sows is around 12 piglets, but litters of 16 to 20 piglets are not uncommon even in gilts although the number of functional teats is usually between 14 and 16 (e.g., Vasdal et al. 2010).

There is a strong neonatal competition for teats even when the number of functional teats equals the number of offspring, and this result in a more or less stable teat order (e.g., Hemsworth et al. 1976; dePassillé and Rushen 1989). During this competition, some piglets will not get access to a teat during milk let-down, will give up fighting after several unsuccessful attempts, and within 2 or 3 days, they will starve to death (e.g., Vasdal et al. 2010). To find a teat and defend it as quickly after birth as possible is thus the most secure "ticket" to survival. If, in other species, the cost to the mother of producing an extra offspring is small and the cost of siblicide is also small, large broods are favored (Parker and Mock 1987).

In addition to sibling competition and siblicidal aggression, parent-offspring conflict may be manifested by reduced maternal care or infanticide. According to the definition of infanticide by Hrdy (1979), this term should include not only physical abuse (i.e., aggressive biting) and direct killing, but also maternal failure and neonatal rejection. From this perspective, crushing by the sow can be viewed as a failure, or lack of willingness, to protect the offspring, and would thus be an alternative way of getting rid of surplus offspring shortly after parturition when maternal investment is still at a low level. Although sows invest relatively little per offspring, their energy expenditure during the lactation period on the litter as a whole is substantial, and this is reflected in the great weight loss in many sows (e.g., reviewed by Drake et al. 2008). As discussed by Ploger (1997), most adaptive models of siblicide and brood reduction in general assume that there is a fixed amount of parental resources. However, we know that this is a simplification and that at least in mammals, a mother with large litters may both consume more food and produce more milk (e.g., reviewed by Mendl 1988; Eissen et al. 2000).

Historically, maternal crushing or overlying by the sow has often been viewed as accidental because the sow may not be aware of the location of all her piglets when she moves around due to the extreme size difference between the mother and offspring. However, recent work reveals that crushing quite often occurs (i.e., in more than $30 \%$ of the incidents) immediately after the mother has nosed or orientated towards the piglets (e.g., Andersen et al. 2005), clearly indicating that she is aware of their presence. Hence, in many cases, crushing of the young in sows may not be accidental.

From the perspective of the mother, maternal infanticide and sibling competition are two mechanisms that have similar effects: by reducing the number of surviving offspring, the amount of resources available for the survivors increases and therefore also their survival prospects (e.g., Drummond et al. 2000; Legge 2002). Although starvation as a consequence of sibling competition may work over a longer time period than maternal crushing, both types of brood reduction are conducted within quite a short time period after birth. Sibling competition is more costly for several reasons: resources are used by offspring that do not survive; some resources are expended by the surviving offspring in order to prevail in the competition; and aggressive competition for access to teats may cause discomfort and unsuccessful nursings for the sow. Although infanticide (i.e., maternal crushing) might be less costly for the mother, sibling competition is likely to be a more precise mechanism for ensuring that the largest and most healthy offspring survive. Temme (1989) and Heigh (1990) showed that equal investment in all offspring does not maximize parental fitness if a parent can detect differences in quality between litter mates. It has not been documented whether sows selectively differentiate between their offspring by investing more in offspring with high survival chances, but the heaviest and most vital at birth (i.e., with a high rectal temperature shortly after birth), and those that are born early in the birth order are most successful in competing for teats and thus most likely to 
survive (dePassillé et al. 1988; reviewed by Drake et al. 2008; Vasdal et al. 2010; Pedersen et al. unpublished). Furthermore, hungry piglets (i.e., the ones failing in the competition for teats) are at the highest risk of getting crushed by their mother, because they spend the most time at the udder between bouts of nursing (Weary et al. 1996). As discussed theoretically by Heigh (1990), this is also a method of selective brood reduction, although the mother does not actively reject some of the offspring.

Another major trade-off in life history is between current and future offspring (e.g., Williams 1966; Lessells 1991). Each reproductive effort is associated with a cost in terms of reduced future survival rate or fecundity (Austad 1997; Williams 1966; Gustafsson and Sutherland 1988; reviewed by Forbes 1993; Carey and Gruenfelder 1997). Several avian studies have revealed negative correlations between early and late fecundity (e.g., reviewed by Roff 2002). Also in mammals, such as Japanese macaques (Macaca fuscata) (Tanaka et al. 1970) and, red deer (Cervus elaphus) (Clutton-Brock et al. 1983), females that reproduce in 1 year often have a lower probability of reproducing in the following year. There is a high selection pressure for litter size at birth during the first and second litters in domestic sows compared with other traits in the breeding goal (e.g., the 2009 breeding goal for Norwegian Landrace sows). The fact that sows give birth to larger and larger litters early in life may result in a substantial decline in maternal investment in later litters, since the biological system controlling the trade-off between current and future reproductive output is strongly under genetic control and most likely cannot be overshadowed by domestication or artificial selection (e.g., reviewed by Andersen et al. 2006). The importance of parity for reproductive performance is not well documented in domestic species, and thus needs to be systematically studied.

As avian studies still dominate the theoretical discussions and empirical studies of maternal investment and sibling competition (e.g., reviewed by Hudson and Trillmich 2008), the present paper contributes to our knowledge about mammalian brood reduction (e.g., Mock and Parker 1997; Drummond et al. 2000). Furthermore, as opposed to several studies on parent-offspring conflict in mammals (e.g., Parker and Mock 1987; Forbes 1993), the present paper is to our knowledge the only one focusing on the impact of maternal infanticide and sibling competition as two parallel brood reducing mechanisms. The domestic pig, which produces large litters of variable sizes, serves as an excellent animal model to study this in a detailed and controlled manner. The aim of this study was to examine the effects of litter size and parity on sibling competition, piglet survival, and weight gain. Given the simplifying assumption that there is a fixed amount of resources per litter (e.g., Ploger 1997), it was predicted that competition for teats would increase with increasing litter size resulting in some piglets not receiving milk or receiving much less milk than other, more competitive litter mates. This was predicted to increase mortality due to starvation and maternal infanticide, thus keeping the number of surviving piglet constant with increasing litter size. Piglet weight shortly after birth and weight gain from birth until weaning was predicted to decline with increasing litter size. Based on maternal investment theory and the above-mentioned studies of wild species, we also predicted that piglet mortality would be higher for litters born late in a sow's life than earlier and thus that the number of surviving piglets would be higher in early litters.

\section{Materials and methods}

\section{Animals}

In this experiment, 40 healthy, Landrace $\times$ Yorkshire sows of different parities (i.e., giving birth to their first $(n=3)$, second $(n=10)$, third $(n=14)$, or fourth litter $(n=13)$ were used. The criterion for litter size was that no litters should have fewer than eight live born piglets or more than 16 . Litters of fewer than eight are considered rare. Since most sows have between 14 and 16 functional teats (e.g., Vasdal et al. 2010), some sows are able to raise 16 piglets without extra assistance from the farmer. Thus, a litter size of 16 piglets was used as the upper limit. In the analysis of the present study, litter size refers to number of live born piglets at birth.

\section{Routines}

There was no manipulation of litter size, and human interference was kept to a minimum by just feeding, cleaning the pen, and providing new sawdust as bedding material twice a day (at 08:00 and 15:00), providing nest building material (i.e., straw) 1 day before expected birth of the piglets, performing iron injection and castration on day 3 after farrowing (day $0=$ birth of piglets) and providing the piglets with peat litter from 2 weeks after birth. None of the experimental animals required veterinary treatment during the experiment. Before the last observation period at 5 weeks, five sows that were not selected to breed in the next reproduction round were culled. Thus, data from only 35 sows were used to analyze sow behavior at 5 weeks.

The animal environment

During pregnancy, the sows were loose-housed in social groups of 20 to 30 animals, with deep straw bedding on the floor and individual self-closing stalls used for feeding to 
protect the individuals from being chased by others. Two weeks before expected parturition, the sows were moved to a lactation unit where they were loose-housed in individual pens $(2.2 \times 3.0 \mathrm{~m})$, and where they were free to move around, with a triangular piglet creep area placed in one of the front corners of the pen. Two thirds of the sow area had a concrete floor covered with sawdust and one third was made of concrete, slatted flooring. The creep area had floor heating (providing a temperature of $34^{\circ} \mathrm{C}$ for newborn piglets), a thick layer of sawdust and straw, and a suspended roof with a plastic cover hanging down to protect the piglets from draughts. Farrowing rails were placed along the sides of the pen to prevent the sow from crushing piglets against a wall when she was lying down.

Room temperature in the farrowing house was $19^{\circ} \mathrm{C}$ at the time of parturition and was reduced to $17^{\circ} \mathrm{C}, 3$ days after birth. In addition to natural light from the windows, artificial light was provided between 07:30 and 15:00. The sows were given 7 to $8 \mathrm{~kg}$ of straw for nest building the day before expected parturition. In addition to the standard concentrated diet, fed according to a standard scheme for lactating sows, both sows and piglets had free access to water from nipple drinkers in the pen. The piglets were offered ad libitum access to a concentrated diet specialized for small piglets from the age of 2 weeks. Peat litter containing iron ( 0.51 per day) was also given to the piglets from the age of 2 weeks. The piglets were weaned at the age of 5 weeks, and while the sows were moved back to the dry sow unit, the piglets remained in their home pen.

\section{Recordings}

In addition to weighing all the piglets at 1 day, 2.5 and 5 weeks after birth (at the time of weaning), all dead piglets were subjected to a post mortem examination to ascertain the causes of death. This method revealed whether the dead piglet was stillborn (i.e., indicated by uninflated lungs), had received little or no milk at the time of death (judged from the contents of the stomach), or showed signs of crushing (seen on the body surface or as damage to vital organs). It was not possible to diagnose diseases by this method. An experienced veterinarian from The Norwegian Pig Health Service was in charge of the post mortem examinations. In this study, "surviving piglets" refers to the number of piglets that were alive until weaning at the age of 5 weeks.

Six nursings per sow were observed continuously on day 1 , and for 1 day at 2.5 and 5 weeks after birth. The quality of nursing was assessed in terms of nursing interval (minutes between the start of one nursing and the start of the next); whether it was the sow or the piglets that initiated and terminated the nursing; the number of interrupted nursings (where the sow changed posture before milk letdown so that the piglets could not get access to the teats); the number of piglets that did not get access to a teat during each milk let-down (i.e., indicative of sibling competition); and the number of piglets not present at the udder at milk let-down. If the sow was lying down on her side, presenting the udder and grunting, then she was said to be the one initiating the nursing, whereas if the sow was resting on the belly or on the side and two or more piglets started to massage the udder before she started grunting, the piglets were said to have initiated the nursing. If the sow changed posture after milk let-down, so as not to expose the udder anymore, she was said to have terminated the nursing. However, if the piglets fell asleep at the udder and/or left the udder while the sow continued lying on the side in a nursing position, then the piglets were said to have terminated the nursing.

\section{Statistical analysis}

The measures of sow nursing behavior and sibling competition and were mainly analyzed using a mixed ANOVA, including: parity (1 to 4 ) and time after birth (day 1, 2.5 and 5 weeks) as class variables and fixed effects; litter size at birth ( 9 to 16 ) as a continuous variable; the interaction between parity and litter size at birth; and the interaction between time after birth and litter size (Hatcher and Stepanski 1994). Sow (litter) was specified as a random effect in the model.

Variables were not normally distributed on piglet mortality/survival. Therefore, for the analysis of piglet mortality/survival and the proportion of live born piglets that died from different causes, a generalized model, Poisson regression, was conducted by using the GENMOD procedure in SAS with sow parity (1 to 4$)$ as a class variable, litter size at birth as a continuous variable, and the interaction between parity and litter size.

Mean piglet birth weight and weight gain per litter were analyzed using a general linear model (GLM-procedure in SAS), including parity as a class variable, litter size at birth as a continuous variable, and the interaction between them. 0.05 was used as the level of significance.

\section{Results}

Piglet mortality, survival, and weight gain

The number of live born piglets was similar in all parities (GLM, $F_{3,31}=0.2, p=0.93$; parity $1(n=3), 13.3 \pm 1.5$, parity $2(n=9), 13.4 \pm 0.6$, parity $3(n=12), 13.4 \pm 0.6$, parity $4(n=$ $11), 13.9 \pm 0.6)$. Mortality of live born piglets was approximately $20 \% ; 56 \%$ of these deaths were caused by maternal crushing, of which $25 \%$ had not received any milk. Twentysix percent of the dead piglets had no milk in their 
stomachs and were assumed to have starved, since this was the only cause of death. The remaining $18 \%$ died of other causes, and $40 \%$ of these had not received any milk. These other causes included fatal, physical damage because the sow had trampled on them, naval bleeding causing anemia, morphological problems, heart failure, and gastrointestinal disease causing diarrhea.

Concerning the number of surviving piglets, there were no significant effects of litter size, parity (i.e., number of litters farrowed) or the interaction between parity and litter size (Table 1; GENMOD, litter size, $\chi_{1,35}{ }^{2}=0.6, p=0.45$, parity, $\chi_{3,35}{ }^{2}=1.3, p=0.73$, interaction between litter size and parity, $\chi_{3,35}{ }^{2}=1.2, p=0.74$; mean number of surviving piglets for the different parities, parity $1,11.0 \pm 0.6$, parity 2 , $10.7 \pm 0.7$, parity $3,10.3 \pm 0.5$, parity $4,10.2 \pm 0.5$ ). Piglet mortality (percent of live born piglets) increased with increasing litter size and was also affected by parity and the interaction between parity and litter size (Table 1, GENMOD, litter size, $\chi_{1,35}{ }^{2}=96.4, p<0.0001$, parity, $\chi_{3,35}{ }^{2}=54.4, p<0.0001$, interaction between litter size and parity, $\left.\chi_{3,35}{ }^{2}=52.0, p<0.0001\right)$. This was also the case for several causes of mortality, including starved piglets (Table 1, litter size, $\chi_{1,35}{ }^{2}=13.9, p<0.001$, parity, $\chi_{3,35}{ }^{2}=$ 18.7, $p<0.001$, interaction between litter size and parity, $\chi_{3,35}{ }^{2}=13.8, p<0.01$ ) and other causes (Table 1, litter size, $\chi_{1,35}{ }^{2}=16.0, p<0.0001$, parity, $\chi_{3,35}{ }^{2}=8.7, p<0.05$, interaction between litter size and parity, $\chi_{3,35}{ }^{2}=8.7, p<0.05$ ). Maternal crushing of piglets that had not received any milk increased with increasing litter size, but was unaffected by parity (Table 1 , litter size, $\chi_{1,35}{ }^{2}=65.0, p<0.0001$, parity, $\chi_{3,35}{ }^{2}=3.9, p=0.27$, interaction between litter size and parity, $\chi_{3,35}{ }^{2}=3.9, p=0.27$ ), while maternal crushing after receiving milk was affected by parity and the interaction between litter size and parity but not by litter size (Table 1 , GENMOD, litter size, $\chi_{1,35}{ }^{2}=0.3, p=0.56$; parity, $\chi_{3,35}{ }^{2}=$ 19.0, $p<0.001$, interaction between litter size and parity, $\left.\chi_{3,35}{ }^{2}=22.7, p<0.0001\right)$.

Piglet mortality (percent of live born) increased with increasing parity of the sow (Table 1, GENMOD, $\chi_{3,35}{ }^{2}=$
54.4, $p<0.0001$; mean \pm SE values for each parity, parity 1 , $16.5 \pm 4.6$; parity $2,19.3 \pm 4.6$; parity $3,21.5 \pm 4.7$; parity 4 , $26.5 \pm 2.6)$. The percentage of piglets that died of starvation was greater for the oldest sows than for first to third parity sows (Table 1, GENMOD, $\chi_{3,35}{ }^{2}=18.7, p<0.001$; parity 1 , $6.3 \pm 6.3$, parity $2,4.6 \pm 1.9$, parity $3,4.1 \pm 1.3$, parity $4,8.8 \pm$ 2.5 ), but the percent of piglets that were crushed after receiving milk was greatest in third parity sows (Table 1, GENMOD, parity, $\chi_{3,35}{ }^{2}=19.0, p<0.001$; mean \pm SE values for each parity, parity $1,5.6 \pm 2.8$, parity $2,8.7 \pm 5.4$, parity $3,11.8 \pm 2.4$, parity $4,9.6 \pm 2.2$ ). The interactions between litter size and parity showed that for sows in their first, second, and third parities, the percent of starved piglets increased with increasing litter size, but this was not the case for the oldest sows (Table 1, GENMOD, $\chi_{3,35}{ }^{2}=13.8$, $p<0.01)$. Concerning the percent of piglets that were crushed after receiving milk, the interaction between litter size and parity showed that this variable increased with increasing litter size only for third parity sows but not for other parities (Table 1, GENMOD, $\chi_{3,35}{ }^{2}=22.7, p<0.0001$ ).

Mean piglet weight per litter on day 1 decreased with increasing litter size (Fig. 1, GLM, $F_{1,32}=6.9, p=0.013$ ). Mean piglet weight gain from day 1 until 5 weeks after birth also decreased with increasing litter size (Fig. 1, GLM, $\left.F_{1,32}=10.4, p=0.003\right)$. However, there were no significant effects of parity, or the interaction between parity and litter size, on piglet weight on day 1 (GLM, parity, $F_{3,32}=0.9, p=0.45$, interaction between litter size and parity, $F_{3,32}=0.8, p=0.49$ ) or on weight gain (GLM, parity, $F_{3,32}=0.6, p=0.60$, interaction between litter size and parity, $F_{3,32}=1.4, p=0.27$ ).

\section{Sibling competition}

The number of piglets failing to get access to a teat during milk let-down increased with increasing litter size on day 1 , but there was no such relationship at 2.5 or 5 weeks of age (Fig. 2, ANOVA, litter size, $F_{1,63}=0.3, p=0.61$, parity, $F_{3,63}=$ 2.8, $p=0.046$, time period, $F_{2,63}=2.4, p=0.10$, interaction

Table 1 The effects of litter size, sow parity, and the interaction between them on piglet survival and mortality and the different causes of mortality

\begin{tabular}{|c|c|c|c|c|c|c|}
\hline & \multicolumn{2}{|c|}{ Litter size } & \multicolumn{2}{|l|}{ Parity } & \multicolumn{2}{|c|}{ Interaction between litter size and parity } \\
\hline & $\chi_{1,35}^{2}$ & $p$ value & $\chi_{3,35}^{2}$ & $p$ value & $\chi_{3,35^{2}}$ & $p$ value \\
\hline Number of surviving piglets & 0.6 & 0.45 & 1.3 & 0.73 & 1.2 & 0.74 \\
\hline Piglet mortality ( $\%$ of live born) & 96.4 & $<0.0001$ & 54.4 & $<0.0001$ & 52.0 & $<0.0001$ \\
\hline Maternal crushing/no milk ( $\%$ of dead piglets) & 65.0 & $<0.0001$ & 3.9 & 0.27 & 3.9 & 0.27 \\
\hline Maternal crushing/milk ( $\%$ of dead piglets) & 0.3 & 0.56 & 19.0 & $<0.001$ & 22.7 & $<0.0001$ \\
\hline No milk, i.e. starved ( $\%$ of dead piglets) & 13.9 & $<0.001$ & 18.7 & $<0.001$ & 13.8 & $<0.01$ \\
\hline Other causes ( $\%$ of dead piglets) & 16.0 & $<0.0001$ & 8.7 & $<0.05$ & 8.7 & $<0.05$ \\
\hline
\end{tabular}




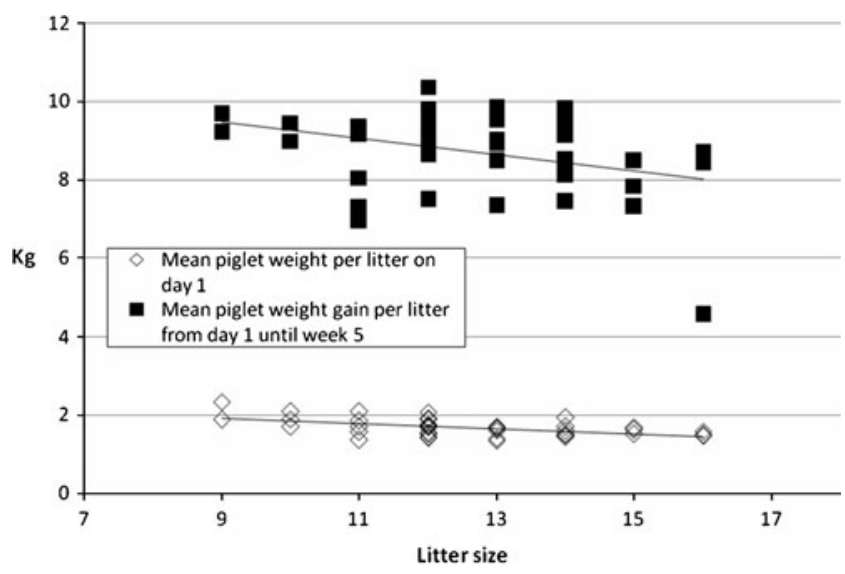

Fig. 1 Mean piglet weight at day 1 post partum and mean weight gain until 5 weeks of age $(n=40$ litters; distributed across the following litter sizes, $9, n=2,10, n=2,11, n=5,12, n=11,13, n=6,14, n=6,15$, $n=5,16, n=3$ ) with increasing litter size

between litter size and parity, $F_{3,63}=2.6, p=0.07$, interaction between litter size and time period, $F_{2,63}=5.1, p=0.009$ ). Mean \pm SE number of piglets failing to get access to a teat during milk let-down for the different litter sizes, respectively, was $0.4 \pm 0.3$ for 9 piglets $(n=2), 0.9 \pm 0.7$ for 10 piglets $(n=$ 2), $0.4 \pm 0.2$ for 11 piglets $(n=5), 1.1 \pm 0.2$ for 12 piglets $(n=$ 11), $1.9 \pm 0.5$ for 13 piglets $(n=6), 1.8 \pm 0.4$ for 14 piglets $(n=$ 6), $1.7 \pm 0.4$ for 15 piglets $(n=5)$, and $1.8 \pm 0.3$ for 16 piglets $(n=3)$. Similar to what was found concerning the number of piglets failing to get access to a teat, an interaction was found between litter size and parity and between litter size and time period with respect to the number of piglets not present at the udder at milk let-down (i.e., not competing for a teat; Fig. 2, ANOVA, litter size, $F_{1,63}=0.9, p=0.35$, parity, $F_{3,63}=5.2, p=$ 0.003 , time period, $F_{2,63}=4.8, p=0.011$, interaction between litter size and parity, $F_{3,63}=5.8, p=0.002$, interaction between litter size and time period, $F_{2,63}=5.9, p=0.005$ ). The number of piglets failing to get access to a teat during milk let-down declined with the parity of the sow (ANOVA, parity, $F_{3,63}=$ $2.8, p=0.046)$. The number of piglets not present at milk letdown increased with increasing litter size in older sows (parity 3 and 4) but not in younger sows (parity 1 and 2) (ANOVA, interaction between litter size and parity, $F_{3,63}=$ $5.8, p=0.002)$.

Sow nursing behavior

The proportion of nursings initiated by the sow declined over the lactation period, but this change was not significant (ANOVA, $F_{2,65}=2.8, p=0.07$; day $1,95.8 \pm$ $1.9 \%, 2.5$ weeks, $50.0 \pm 5.1 \%, 5$ weeks, $18.1 \pm 3.4 \%$ ). There were no significant effects of litter size (ANOVA, $F_{1,65}=$ $0.0, p=0.91$ ), parity (ANOVA, $F_{3,65}=0.9, p=0.47$ ), the interaction between litter size and parity (ANOVA, $F_{3,65}=$ $0.8, p=0.49$ ), or the interaction between litter size and time period (ANOVA, $F_{2,65}=0.1, p=0.90$ ) on the proportion of nursings initiated by the sow (overall mean \pm SE, $56.6 \pm$ $3.7 \%$ ). Furthermore, time period, litter size, and the interactions between them had no effect on the proportion of interrupted nursings (ANOVA, litter size, $F_{1,65}=1.2, p=$ 0.29 , parity, $F_{3,65}=0.8, p=0.48$, time period, $F_{2,65}=0.2, p=$ 0.81 , interaction between litter size and parity, $F_{3,65}=0.9$, $p=0.43$, interaction between litter size and time period, $F_{2,65}=0.1, p=0.45$; overall mean $\pm \mathrm{SE}, 11.4 \pm 1.5 \%$ ), the proportion of nursings terminated by the sow (ANOVA, litter size, $F_{1,65}=1.1, p=0.30$, parity, $F_{3,65}=0.2, p=0.91$, time period, $F_{2,65}=0.9, p=0.42$, interaction between litter size and parity, $F_{3,65}=0.4, p=0.79$, interaction between litter size and time period, $F_{2,65}=1.7, p=0.18$; overall mean $\pm \mathrm{SE}, 48.3 \pm 3.6 \%$ ), or the mean time interval between the six recorded nursings (ANOVA, litter size, $F_{1,65}=0.0$, $p=0.96$, parity, $F_{3,65}=0.3, p=0.80$, time period, $F_{2,65}=0.6$, $p=0.55$, interaction between litter size and parity, $F_{3,65}=$ $0.4, p=0.73$, interaction between litter size and time period, $F_{2,65}=0.5, p=0.62$; overall mean $\pm \mathrm{SE}, 58.0 \pm 2.4 \mathrm{~min}$ ).

\section{Discussion}

As predicted, piglet mortality due to both maternal infanticide (i.e., crushing) of starving piglets (i.e., crushed piglets with no milk in their stomachs) and starvation caused by increased sibling competition, increased with litter size, resulting in a constant number of survivors. A positive relationship between litter size and piglet mortality is already documented (e.g., Pedersen et al. 2006; Weber et

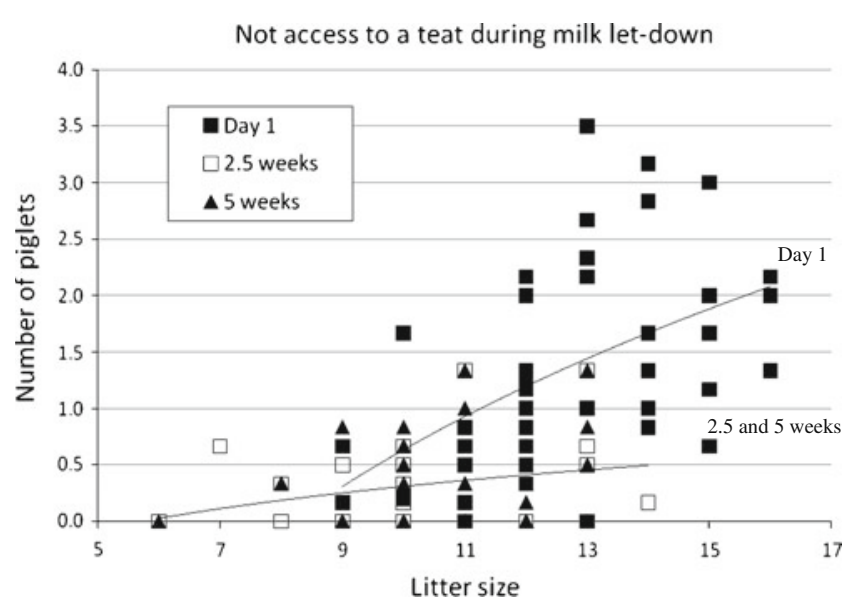

Fig. 2 Mean number of piglets not getting access to a teat during milk let-down on day 1 ( $n=40$ litters; distributed across the following litter sizes, 9, $n=2,10, n=2,11, n=5 ; 12, n=11,13, n=6,14, n=6,15, n=$ $5,16, n=3)$, and at 2.5 weeks ( $n=40$ litters; distributed across the following litter sizes, $6, n=1,7, n=1,8, n=2,9, n=5,10, n=7,11, n=$ $11 ; 12, n=9,13, n=3,14, n=1)$ and 5 weeks ( $n=34$ litters; distributed across the following litter sizes, $6, n=1,8, n=2,9, n=3,10, n=6,11$, $n=12 ; 12, n=6,13, n=4)$ of age 
al. 2009), but few have looked into the different causes of mortality and the mechanisms that lie behind this. Since maternal crushing increased with increasing litter size only for the piglets that had not received milk, it appears that maternal crushing of piglets is more selective than we originally predicted. Piglets that have consumed milk are often more vital and robust and, can get away from the sow more quickly, or they simply spend less time close to the sow outside the time of nursing because they are not hungry (Weary et al. 1996). Aggression towards young and killing of own offspring are documented to some extent in captive wild boar (e.g., Harris et al. 2001). Some of the existing data suggest that infanticide in terms of killing and eating own and other sows offspring may exist also in free-living populations (e.g., Gundlach 1968; Lands Management Personnel and U.S. Forest Service 1990). Data collected from a wild boar population of almost 500 pigs in Tennessee, reveals that mortality rates could be more than $38 \%$, even with a small litter size of five piglets (Lands Management Personnel and U. S. Forest Service 1990), and the rate of crushing observed in captive wild boar was surprisingly similar to what is reported in today's domestic pigs.

As a consequence of the strongly increasing sibling competition with increasing litter size, piglet weight at day 1 and growth until weaning also declined, as predicted. Similar results have been found in several avian and mammalian studies (e.g., Priestnall 1972; Mendl 1988; Guerra and Nunes 2001; Nilsson and Gårdmark 2001), and this is also documented in domestic pigs (Tuchscherer et al. 2000; Milligan et al. 2002; Wolf et al. 2008). As in the present study, Milligan et al. (2002) reported that piglets with a low birth weight usually had a low weight at weaning, which means that the competitive disadvantage of the smaller piglets compared to the large ones remains throughout the lactation period.

Of the three main hypothesis proposed to explain maternal overproduction, the results from pigs support the hypothesis that this can serve as a replacement for members of the brood that are likely to die (Mock and Forbes 1995; Mock and Parker 1997, 1998; Forbes and Mock 1998). In sows that are kept in a loose-housed environment, where they are able to have more control over their maternal investment than in a farrowing crate, $86 \%$ of the mortality of live born piglets occurs within the first 2 days after farrowing (e.g., Andersen et al. 2005), and this is usually caused by maternal crushing, starvation, or a combination of both. Furthermore, hypothermic (i.e., weak) piglets and piglets born late in the birth order suffer a higher risk of dying (Vasdal et al. 2010; Pedersen et al. unpublished). Asynchronous hatching also produces nestlings differing in quality and survival chances (e.g., Legge 2002). Legge (2002) showed in her paper on siblicide in the laughing kookaburra (Dacelo novaeguineae) that when early deaths of surplus offspring were caused by the oldest nestling directly killing the youngest, rather than through a prolonged process of starvation, this enhanced the growth and survival prospects of the eventual survivors. The consequences of early death (through maternal crushing) versus prolonged starvation (through increased sibling competition) for the weight of the surviving piglets have not been studied, but as has been elegantly demonstrated in domestic rabbits (Oryctolagus cuniculus; Drummond et al. 2000), it is likely that the most successful competitors for milk will benefit most from the deaths of their litter mates by obtaining more resources if this occurs soon after birth.

The hypothesis that mothers are tracking environmental variation could also be relevant for overproduction of young in wild boars, as for instance the degree of infanticide may increase when there is a lack of resources. In domestic sows, however, the availability of food has been stable throughout their selection history within the production environment. There is no support for the hypothesis of developmental facilitation among the piglets, either by serving as food or by other means of helping the survival prospects of their litter mates (e.g., Forbes and Mock 1998).

Neonatal competition and mortality among newborn piglets have strong parallels with "facultative siblicide," which adjusts brood size in several species of birds (e.g., Mock 1984, 1987; Fraser et al. 1995), and is also reported in other mammals such as the spotted hyena (Crocuta crocuta; Frank et al. 1991) and several species of canids (Bekoff 1972, 1974). As in hyena pups, the fierce aggressive competition among piglets starts immediately after birth (Fraser and Thomson 1991). The piglets' third incisors, orientated like canines, are particularly efficient weapons specialized for neonatal aggressive competition. An interesting feature of these teeth is that this orientation is only seen immediately after birth. Later when the competition is less intense, they become increasingly forward orientated as is typical for other incisors. These teeth may harm other piglets and may also result in discomfort and painful nursing for the sow if the teats are wounded (e.g., Fraser 1975). However, in contrast to the many avian examples of fatal sibling competition, competition among piglets can best be described as sub-lethal because it does not have immediate fatal consequences (e.g., Mock and Parker 1997). It does not exactly fit theoretical models in which there is either a rigid dominance order where individuals share resources according to their rank order, or a "begging scramble" where offspring gain according to their relative begging levels (Macnair and Parker 1979; Parker et al. 1989). Rather, competition among newborn piglets involves both mechanisms working simultaneously: begging from hungry piglets with low teat success 
(e.g., Weary et al. 1996) and fights to establish a teat order (e.g., dePassillé and Rushen 1989).

Although there are several studies showing that the anterior teats are more productive than the rest (e.g., Gill and Thomson 1956; Fraser et al. 1979), there is little documentation to support differences in teat quality for the rest of the udder. So, the number of surplus piglets that eventually die because they cannot hold on to a teat position should be equal to the difference between number of functional teats and the actual litter size. The present study shows that this is not the case. Although domestic sows have on average 15 functional teats (ranging from 13 to 17; Vasdal et al. 2010), the present study documented that on average, one piglet per nursing did not receive any milk during milk-let-down already at a litter size of 12 piglets. This suggests that if the teats do not differ much in quality, piglets with a high competitive ability may monopolize more than one teat early after birth when a strict nursing interval is still not fully developed. This is indeed the case, as one piglet can sample around seven teats during the first $8 \mathrm{~h}$ after birth, thereby maximizing colostrum intake (dePassillé et al. 1988; dePassillé and Rushen 1989). However, it is not known how long this resource monopolization lasts or if it continues after a teat order is established. Another factor might be that domestic sows appear to have less functional udders in that the lower row of teats is not easily accessible shortly after birth. This problem increases with increasing parity of the sows, probably because the size of the udder and the body itself become bigger with age (Vasdal et al. unpublished).

Current reproduction may reduce future survival for the parent and hence reduce the reproductive chances in the future (Bell 1980; Lessells 1991; Forbes 1993; Carey and Gruenfelder 1997). Fourth parity sows lost more piglets due to starvation than younger sows, but in contrast to what was predicted, there was no relationship between sow parity and number of surviving piglets. In fact, the number of surviving piglets was surprisingly stable at a level of 10 to 11 piglets across all parities, suggesting that this is the biological capacity of a sow irrespective of age. Similar results on mortality were found by Weber et al. (2009) and Weary et al. (1998). In contrast, Held et al. (2006) found no clear relationship between sow parity and piglet mortality, but documented a reduction in sow responsiveness to the piglets with increasing parity.

The effects of the treatments on nursing behavior were minor, and it is likely that variables related to nursing behavior are not the best indicators to distinguish successful from unsuccessful mothers in terms of piglet survival (e.g., Andersen et al. 2005).

In conclusion, piglet mortality caused by maternal crushing of piglets with no teat success and starvation caused by sibling competition, increased with increasing litter size for most sow parities. This resulted in a more or less constant number of surviving piglets at the time of weaning and suggests that 10 to 11 piglets could be close to the upper limit that the domestic sow is capable of taking care of.

Acknowledgements This project was financed by the Norwegian Research Council. We would like to thank the farmer, Bjørn Gevelt, for letting us stay on the farm and use his sows and litters. We are also very grateful to Ellen Rosvold, Kari E. Schjerpen, Grete H. M. Jørgensen, and Ingeborg Anni Haukvik who took part in the data collection. Finally, we would like to thank professor Per Jensen for constructive advice when planning the experiment and Dr. Richard Kirkden and professor Donald Broom for valuable comments on the manuscript. The present experiment complies with the current laws in Norway (www.lovdata.no). The authors declare that they have no conflict of interest.

Open Access This article is distributed under the terms of the Creative Commons Attribution Noncommercial License which permits any noncommercial use, distribution, and reproduction in any medium, provided the original author(s) and source are credited.

\section{References}

Andersen IL, Berg S, Bøe KE (2005) Crushing of piglets by the mother sow (Sus scrofa) - purely accidental or a poor mother? Appl Anim Behav Sci 93:229-243

Andersen IL, Nævdal E, Bøe KE, Bakken M (2006) The significance of theories in behavioural ecology for solving problems in applied ethology - possibilities and limitations. Appl Anim Behav Sci 97:85-104

Austad SN (1997) Postreproductive survival. In: Wachter KW, Finch CE (eds) Between Zeus and the Salmon. National Academy Press, Washington, pp 161-174

Bekoff M (1972) The development of social interactions, play, and metacommunication in mammals: an ethological approach. Behav Biol 47:412-434

Bekoff M (1974) Social play and play soliciting by infant canids. Am Zool 14:323-340

Bell G (1980) The costs of reproduction and their consequences. Am Nat 116:45

Carey JR, Gruenfelder C (1997) Population biology of the elderly. In: Wachter KW, Finch CE (eds) Between Zeus and the Salmon. National Academy Press, Washington, pp 127-160

Clutton-Brock TH, Guinnes FE, Albon SD (1983) The costs of reproduction in red deer hinds. J Anim Ecol 52:367-383

dePassillé AMB, Rushen J (1989) Suckling and teat disputes by neonatal piglets. Appl Anim Behav Sci 22:23-38

dePassillé AMB, Rushen J, Pelletier G (1988) Suckling behaviour and serum immunoglobulin levels in neonatal piglets. Anim Prod $47: 447-456$

Drake A, Fraser D, Weary DM (2008) Parent-offspring resource allocation in domestic pigs. Behav Ecol Sociobiol 62:309-319

Drummond $\mathrm{H}$, Vàzquez $\mathrm{E}$, Sànchez-Colòn $\mathrm{S}$, Martinez-Gòmez $\mathrm{M}$, Hudson R (2000) Competition for milk in the domestic rabbit: survivors benefit from litter mate deaths. Eth 106:511-526

Eissen JJ, Kanis E, Kemp B (2000) Sow factors affecting voluntary feed intake during lactation. Livest Prod Sci 64:147-165

Emsley A, Dickerson GE, Kashyap TS (1977) Genetic parameters in progeny test selection for field performance of strain-cross layers. Poultry Sci 56:121-146

Forbes LS (1993) Avian brood reduction and parent-offspring 'conflict'. Am Nat 142:82-117 
Forbes LS, Mock DG (1998) Parental optimism and progeny choice: when is screening for offspring quality affordable? J Theor Biol 192:3-14

Frank LG, Glickman SE, Licht P (1991) Fatal sibling aggression, presocial development, and androgens in neonatal spotted hyaenas. Science 252:702-704

Fraser D (1975) The 'teat order' of suckling pigs. II. Fighting during suckling and the effects of clipping eye teeth. J Agric Sci 84:393-399

Fraser D, Thomson BK (1991) Armed sibling rivalry among suckling piglets. Behav Ecol Sociobiol 29:9-15

Fraser D, Thompson BK, Ferguson DK, Darroch RL (1979) The 'teat order' of suckling pigs. J Agric Sci 92:257-261

Fraser D, Kramer DL, Pajor EA, Weary DM (1995) Conflict and cooperation: sociobiological principles and the behaviour of pigs. Appl Anim Behav Sci 44:139-157

Gill JC, Thomson W (1956) Observations on the behaviour of suckling piglets. Br J Anim Behav 4:46-51

Guerra RF, de Nunes CRO (2001) Effects of litter size on maternal care, body weight and infant development in golden hamsters (Mesocricetus auratus). Behav processes 55:127-142

Gundlach VH (1968) Brutfürsorge, Brutpflege, Verhaltensontogenese und tagesperiodik beim Europäishen Wildschwein (Sus scrofa L.) Zeitschrift für Tierpsychologie 25: 955-995

Gustafsson L, Sutherland WJ (1988) The costs of reproduction in the collard flycatcher, Ficdula albicollis. Nature 335:813-815

Harris MJ, Bergeron R, Gonyou HW (2001) Parturient behaviour and offspring-directed aggression in farmed wild boar of three genetic lines. Appl Anim Behav Sci 74:153-163

Hatcher L, Stepanski EJ (1994) A step-by-step approach to using the SAS $^{\circledR}$ system for univariate and multivariate statistics. SAS Institute Inc, Cary, p 552

Heigh D (1990) Brood reduction and optimal parental investment when offspring differ in quality. Am Nat 136:550-556

Held S, Mason G, Mendl M (2006) Maternal protectiveness of outdoor sows from first to fourth parities. Appl Anim Behav Sci 98:216-233

Hemsworth PH, Winfield CG, Mullaney PD (1976) A study of the teat order in piglets. Appl Anim Ethol 2:225-233

Hogsett ML, Nordskog AW (1958) Genetic economic value in selecting for egg production rate, body weight and egg weight. Poultry Sci 37:1404-1417

Hrdy SB (1979) Infanticide among animals: a review, classification, and examination of the implications for the reproductive strategies of females. Ethol Sociobiol 1:13-40

Hudson R, Trillmich F (2008) Sibling competition and cooperation in mammals: challenges, developments and prospects. Behave Ecol Sociobiol 62:299-307

Kozlowski J, Stearn SC (1989) Hypotheses for the production of excess zygotes, models of bet-hedging and selective abortion. Evol 43:1369-1377

Lack D (1947) The significance of clutch size. Ibis 89:302-352

Lands Management Personel and U.S. Forest Service (1990) Wildlife research report, W-34. European Hog Research, Tennessee Wildlife Resources Agency, pp 259

Legge S (2002) Siblicide, starvation and nestling growth in the laughing kookaburra. J Avian Biol 33:159-166

Lessells CM (1991) The evolution of life histories. In: Krebs JR, Davies NB (eds). Behavioral Ecology - An Evolutionary Approach, 3rd edition, Blackwell Scientific Publications, Oxford, pp 32-68

Lund MS, Puonti M, Rydhmer L, Jensen J (2002) Relationship between litter size and perinatal and pre-weaning survival in pigs. Anim Sci 74:217-222

Macnair M, Parker GA (1979) Model of parent-offspring conflict. III. Intra-brood conflict. Anim Behav 27(27):1202-1209

Mendl M (1988) The effects of litter size variation on motheroffspring relationships and behavioural and physical development in several mammalian species. J Zool Lon 215:15-34
Milligan BN, Fraser D, Kramer DL (2002) Within-litter birth weight variation in the domestic pig and its relation to pre-weaning survival, weight gain, and variation in weaning weight. Livest Prod Sci 76:181-191

Mock DW (1984) Infanticide, siblicide and avian nestling mortality. In: Hausfater G, Hrdy SB (eds) Infanticide: comparative and evolutionary perspectives. Aldine, New York, pp 3-30

Mock DW (1987) Siblicide, parent-offspring conflict, and unequal parental investment by egrets and herons. Behav Ecol Sociobiol 20:247-256

Mock DW, Forbes LS (1995) The evolution of parental optimism. Trends Ecol Evol 10:130-134

Mock DW, Parker GA (1997) The evolution of sibling rivalry. Oxford series in ecology and evolution, Oxford University press, Oxford, p 464

Mock DW, Parker GA (1998) Siblicide, family conflict and the evolutionary limits of selfishness. Rev Anim Behav 56:1-10

Nilsson J-Å, Gårdmark A (2001) Sibling competition affects individual growth strategies in marsh tit, Parus palustris, nestlings. Anim Behav 61:357-365

Nur N (1984) The consequences of brood size for breeding blue tits. II. Nestling weight, offspring survival, and optimal brood size. J Anim Ecol 53:497-517

Parker GA, Mock DW (1987) Parent-offspring conflict over clutch size. Evol Ecol 1:161-174

Parker GA, Mock DW, Lamey TC (1989) How selfish should stronger sibs be? Am Nat 133:846-868

Pedersen LJ, Jørgensen E, Heiskanen T, Damm BI (2006) Early piglet mortality in loose-housed sows related to sow and piglet behaviour and to the progress of parturition. Appl Anim Behav Sci 96:215-232

Ploger BJ (1997) Does brood reduction provide survivors with a food bonus? Anim Behav 54:1063-1076

Priestnall R (1972) Effects of litter size on the behaviour of lactating female mice (Mus musculus). Anim Behav 20:386-394

Roff DA (2002) Life history evolution. Sinauser, Sunderland, U. S. A., pp 527

Smith CC, Fretwell SD (1974) The optimal balance between the size and number of offspring. Am Nat 108:499-506

Smith HG, Källander H, Nilsson JA (1989) The trade-off between offspring number in the great tit Parus major. J Anim Ecol 58:383-402

Tanaka T, Tokuda K, Kotero S (1970) Effects of infant loss on the inter-birth interval of Japanese monkeys. Primates 11:113-117

Temme DH (1989) Seed size variability: a consequence of variable genetic quality among offspring? Evol 40:414-417

Tuchscherer M, Puppe B, Tuchscherer A, Tieman U (2000) Early identification of neoanates at risk: traits of newborn piglets with respect to survival. Theriogenologi 54:371-388

Vasdal G, Østensen I, Melišová M, Bozděchová B, Illman G, Andersen I L (2010) Management routines at the time of farrowing - effects on teat success and piglet mortality in loose housed sows. Livest Sci (in press)

Weary DM, Pajor EA, Thompson K, Fraser D (1996) Risky behaviour by piglets: a trade off between feeding and risk of mortality by maternal crushing? Anim Behav 51:619-624

Weary DM, Phillips PA, Pajor EA, Fraser D, Thompson BK (1998) Crushing of pioglets by sows: effects of litter features, pen features and sow behaviour. Appl Anim Behav Sci 61:101-111

Weber R, Keil NM, Fehr M, Horat R (2009) Factors affecting piglet mortality in loose farrowing systems on commercial farms. Livest Sci 124:216-222

Williams GC (1966) Natural selection, the cost of reproduction, and a refinement of Lack's principle. Am Nat 100:687-690

Wolf J, Zakovà E, Groenveld E (2008) Within-litter variation of birth weight in hyperprolific Czech large white sows and its relation to litter size traits, stillborn piglets and losses until weaning. Livest Sci 115:195-205 